\title{
Goalbox activity as a measure of frustration in a single runway*
}

\author{
WILLIAM P. DUNLAP†, LARRY F. HUGHES, THOMAS J. O'BRIEN, \\ JOEL H. LEWIS, and LAWRENCE DACHOWSKI \\ Tulane University, New Orleans, La. 70118
}

Activity following nonreward in a single runway was measured, using a stabilimeter as the floor of the goalbox. Performance of partially reinforced Ss was compared to activity of continuously rewarded and never rewarded control groups. A substantial frustration effect was found above control group levels, establishing the validity of this procedure for measuring frustration produced by nonreward in terms of increments in general activity.

Miller \& Stevenson (1936) reported what they termed "agitated" behavior to be an increasing function of the number of extinction trials in a runway. They commented on the explosive energization of behavior produced by nonrewarded trials and suggested experiments employing an alley whose floor was a stabilimeter. Beginning with Amsel \& Roussel (1952), a number of studies using the double alley have demonstrated the energization of running in the second alley produced by the lack of a previously experienced reward in the first alley; this increase in second-alley speed has been termed the frustration effect (FE). Tacker \& Way (1968) observed ambulation and rearing in rats following the omission of reward in an open-field arena that served as the goalbox of a straight runway. A significant increase in ambulation and rearing was found following the first three of six nonrewarded test trials, but the effect disappeared by the fifth and sixth trials, which is clearly atypical of the FE found in the double alley (e.g., McHose, 1963). Gallup \& Altomari (1969) have also criticized this study on the grounds that ambulation may have been instrumentally conditioned by pretraining $S s$ in the open field with food pellets scattered about the floor. Gallup and Altomari found a consistent increase in ambulation and rearing following nonrewarded trials when compared to rewarded trials, even though Ss were removed from the goalbox of the runway and observed in a physically separate open-field arena. Gallup \& Hare (1969), using the same procedure, compared a $50 \%$ partially rewarded group to a continuously

* This research was supported in part by funds from a PHS Biomedical Sciences Support Grant to Tulane University. Data analysis was supported by the Tulane University Computer Center.

tRequests for reprints should be sent to William P. Dunlap, Department of Psychology, Tulane University. New Orleans, La. 70118. reinforced group and found significant increases in activity following both rewarded and nonrewarded trials for $50 \%$ Ss when compared to continuously rewarded Ss.

None of the above activity studies, however, have employed the never rewarded $0 \%$ control group proposed by Wagner (1959) as necessary to demonstrate that increases in response following nonreward are attributable to frustration rather than demotivation or response depression produced by reward. Furthermore, frustration following nonreward should be less pronounced when the $S$ is removed from the goalbox situation (Amsel, 1958). Removal of the $S$ from specific frustrative cues occurs in both the double runway situation and in a physically separate activity arena. A procedure that allows measurement of activity in the goalbox and yet avoids the difficulties of the Tacker \& Way (1968) study should provide an extremely sensitive measure of general energization produced by frustration.

The present experiment employed a straight alley in which the goalbox floor was a stabilimeter platform. A 50\% partially reinforced group was compared to both a continuously rewarded $100 \%$ group and the $0 \%$ control group suggested by Wagner (1959).

\section{SUBJECTS}

Forty-eight experimentally naive male albino rats obtained from the Dan Rolfsmeyer Co., Madison, Wisconsin, served as Ss. They were housed in individual cages in a room with a reversed light-dark cycle, with water available ad lib. Ss were 90 days old and averaged $325.1 \mathrm{~g}(\mathrm{SD}=17.08)$ at the beginning of deprivation.

$$
\text { APPARATUS }
$$

The straight alley consisted of a 34.3-cm startbox (SB), a 40.6-cm runway ( $R W$ ), and a square $30.5 \times 30.5 \mathrm{~cm}$ goalbox (GB). All sections of the alley were $9.5 \mathrm{~cm}$ high; SB and RW were $7.6 \mathrm{~cm}$ wide. The apparatus was made of wood and painted black, with the exception of the translucent plastic top of $R W$ and the floors of SB and GB, which were perforated aluminum stabilimeter platforms (Lafayette Instrument Co., Model A501). SB was separated from RW by a Hunter automatic double door gate (Model 393). A manually operated guillotine door prevented retracing from GB. Photocells were positioned in RW 5.7 and $36.2 \mathrm{~cm}$ from the SB door. The black plastic foodcup was in a $5.7 \times 5.1 \mathrm{~cm}$ recess, $6.7 \mathrm{~cm}$ deep, in the far wall of GB. A third photocell above the foodcup activated the food delivery mechanism. The stabilimeter amplifier (maintained at Setting 8) was sensitive enough to pick up major movements. Stabilimeter pulses were recorded on one electromechanical counter for $8 \mathrm{sec}$ following the first pulse from $\mathrm{GB}$, then on a second counter for 12 more seconds. Time intervals were controlled by Hunter Decade Interval Timers (Model 111C). The apparatus was illuminated from above by two red $10 \cdot \mathrm{W}$ bulbs.

\section{PROCEDURE}

The Ss were assigned randomly to groups $(0 \%, 50 \%$, or $100 \%) 12$ days following their arrival and were placed on a 2-h-per-day feeding schedule, which was continued throughout the experiment. Following 9 days' adaptation to the deprivation schedule, Ss began an 11-day pretraining period during which they received reward pellets (45-mg Noyes) in the home cage and were allowed to explore GB. The $0 \%$ Ss were fed reward pellets in the home cage, but never in GB. Ss were fed decreasing numbers of reward pellets until on the last 4 pretraining days all Ss were fed three pellets in the home cage and were placed four times each day in GB; $50 \%$ and $100 \%$ Ss obtained three pellets from the foodcup in GB each time.

During runway training Ss were run in squads of six, containing two Ss from each group. Between any two trials for a given $S$, the five other Ss in his squad were run, maintaining an intertrial interval of approximately $8 \mathrm{~min}$. Running order within squads was randomized each day. Four Es ran two squads each for a total of eight squads. On the first and second days of training, 2 trials were given; on the third day, 4 trials were given; then 8 trials were given each day for 8 more days for a total of 72 training trials. On each trial, $S$ was moved from his home cage to $S B$. The opaque and transparent doors opened automatically 6 and $9.2 \mathrm{sec}$, respectively, following closure of the SB lid. When S entered GB, a door was 
lowered manually to prevent retracing. Recording of GB activity was initiated automatically by the first activity pulse from GB. Activity in GB was recorded during two time segments, the initial $8 \mathrm{sec}$ and subsequent $12 \mathrm{sec}$ It was determined in preliminary observations that most Ss would eat the three-pellet reward within the first $8 \mathrm{sec}$; thus, a comparison of activity following reward (R) and nonreward( $N)$ during the later $12-\mathrm{sec}$ period should be much less influenced by the presence or absence of eating behavior. The $100 \%$ Ss were rewarded on every trial, $0 \%$ Ss were never rewarded, and $50 \%$ Ss received $\mathrm{N}$ and $\boldsymbol{R}$ trials in sequences chosen such that every two trials was an $R, N$ pair. With eight trials, there are 16 such sequences. Each day the $1650 \%$ Ss were assigned randomly to the 16 possible sequences, with the restriction that no $S$ ever repeated a given sequence. If $\mathrm{S}$ took longer than $60 \mathrm{sec}$ to complete any alley segment, he was manually placed in the next segment. After 20 sec in GB, $\mathbf{S}$ was returned to the home cage. Ss were fed immediately after training each day, and any $\mathrm{S}$ weighing less than $80 \%$ of ad lib weight was given extra feeding.

\section{RESULTS}

Fifty percent group goalbox activity scores were analyzed for the first $8 \mathrm{sec}$ and following $12 \mathrm{sec}$ of goalbox confinement. As anticipated, the results from the first $8 \mathrm{sec}$ of measurement were rather complicated. Although a significant FE in terms of activity was found during the first $8 \mathrm{sec}(\mathrm{F}=48.079, \mathrm{df}=1 / 12, \mathrm{p}<.01)$, there was a significant interaction of FE by Days $(\mathrm{F}=\mathbf{5 . 5 7 5}, \quad \mathrm{df}=8 / 96$ p $<.01)$; also, approximately half of this effect can be accounted for by the superiority of the $0 \%$ group above the rewarded trial activity of the $50 \%$ group. This finding was expected, since on rewarded trials $50 \%$ and $100 \%$ Ss spend part of the initial 8-sec period consuming the reward as opposed to ambulating in GB.

Data from the later 12 -sec period, depicted in Fig. 1, present a much clearer picture. The FE was significant $(F=32.075$, df $=1 / 12, p<.01)$, and the FE did not interact significantly with days. As can be seen, a consistently large FE occurred over days, even though, in general, GB activity declined throughout the course of training ( $F=17.251$, $\mathrm{df}=8 / 96, \mathrm{p}<.01$ ). In terms of overall mean performance, only 3 of the 16 $50 \%$ Ss failed to show a positive FE. The performance of the $50 \%$ group following both reward and nonreward was clearly above $0 \%$ and $100 \%$ control GB activity; therefore, none of the FE obtained by this measure can be accounted for by demotivation due

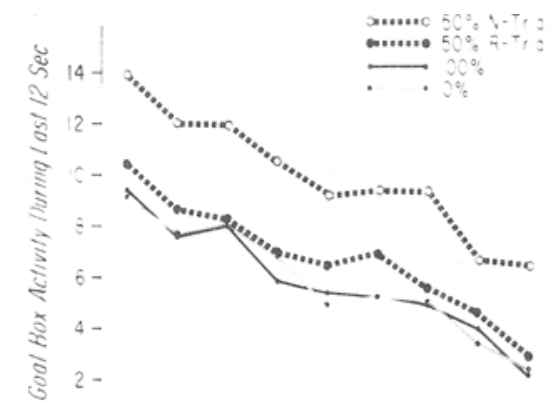

goalbox avoids several problems inherent in the double runway procedure of measuring the effects of frustration: (1) There is no second alley reward, the size of which may interact with G1 reward size in determining the first and second alley speeds in the double runway, as Daly (1968) has pointed out. The FE in the present study cannot be explained as a discrimination phenomenon based on the contrast of first and second alley reward sizes as McHose (1970) has proposed for FEs obtained in the double alley. (2) The stabilimeter procedure does not require that $S$ be removed from the goalbox, the primary source of frustration; thus, this procedure should be substantially more sensitive to effects of frustration than the double runway procedure. Although it is difficult to compare absolute magnitudes across studies and methodologies, the $S$ s in the present study were above $90 \%$ of ad lib body weight by the end of training and yet gave a highly significant $\mathrm{FE}$; at that percent body weight, McHose \& Ludvigson (1964) failed to find a significant $F E$ in the double runway.

\section{REFERENCES}

AMSEL, A. The role of frustrative nonreward in noncontinuous reward situations. Psychological Bulletin, 1958 , 55, 102-119. of the light-dark cycle to show more
activity than those run late in the dark phase; this resulted in an $\mathbf{E}$ by Days interaction $(F=1.852, \quad \mathrm{df}=24 / 96$, $p<.05)$. Average percent of ad lib body weight for all Ss at the beginning of training was $86.19 \%$; by the end of training it was $91.12 \%$.

\section{DISCUSSION}

The finding of a large and consistent $F E$ in the latter $12 \mathrm{sec}$ of $\mathrm{GB}$ confinement in the present study supports the contention of previous investigators that frustration following nonreward can be measured by an increase in general activity rather than by the energization of a particular subsequent response, as in the double runway. The comparison of the obtained FE with the appropriate control groups establishes the claim that the increment in activity following nonreward can be attributed to frustration on $\mathrm{N}$ trials rather than demotivation on $R$ trials. Continuously rewarded, $100 \%$, and never rewarded, 0\%, groups show approximately the same amount and pattern of GB activity, thus yielding ideal control conditions against which to evaluate the FE. The methodology of the present study allows responses to be recorded mechanically rather than by human observation, as was done in previous investigations of activity and partial reinforcement using the open-field arena. The use of a stabilimeter incorporated into the
AMSEL, A., \& ROUSSEL, J. Motivational properties of frustration: I. Effect on a running response of the addition of frustration to the motivational complex. Journal of Experimental Psychology, $1952,43,363-368$.

DALY, H. B. Excitatory and inhibitory effects of complete and incomplete reward reduction in the double runway. Journal of Experimental Psychology, $1968,76,430-438$.

GALLUP, G. G., JR., \& ALTOMARI, T. S. Activity as a postsituational measure of frustrative non reward. Journal of Comparative \& Physiological Psychology, $1969,68,382-384$

GALLUP, G. G., JR. \& HARE, G. K. Activity following partially reinforced trials: Evidence for a residual frustration effect due to conditioned frustration. Psychonomic Science, 1969. 16. 41-42.

McHOSE, J. H. Effect of continued nonreinforcement on the frustration effect. Journal of Experimental Psychology, 1963, 65, 444-450.

McHOSE, J. H. Relative reinforcement effects: $S_{1} / S_{2}$ and $S_{1} / S_{1}$ paradigms in instrumental conditioning. Psy chological Review, 1970, 77, 135-146.

MCHOSE, J. H., \& LUDVIGSON, H. W. Frustration effect as a function of drive. Psychological Reports, 1964, 14, 371-374.

MILLER, N. E., \& STEVENSON, S. S. Agitated behavior of rats during experimental extinction and a curve of spontaneous recovery. Journal of Comparative Psychology, 1936, 21 . 205-231.

TACKER, R. S., \& WAY, J, Motivational properties of nonreward. Psychonomic Science, 1968, 10, 103-104.

WAGNER. A. $R$. The role of reinforcement and nonreinforcement in an "apparent frustration effect." Journal of Experimental Psychology, 1959, 57, 130-136. 